\title{
Risk prediction of water inrush of karst tunnels based on BP neural network
}

\author{
Zhuo Yang \\ State Key Laboratory of Disaster Prevention \& Mitigation of Explosion \&Impact, PLA University of Science \\ and Technology, Nanjing 210007, China
}

\begin{abstract}
To evaluate precisely the risk level of karst tunnel helps reduce the risk of sudden flood water accidents in the process of tunnel construction. On the basis of relevant literature, statistical study and comprehensive analysis of hydrogeological condition in karst tunnel, and select unfavorable geology, formation lithology, underground water level, topography and geomorphology, strata dip Angle, fracture of surrounding rock as risk evaluation index of karst tunnel water gushing. In different hydrogeological conditions, varies a lot. Using BP neural network method to analysis water gushing risk of karst tunnel and avoid the weight of factors. In engineering applications, assess water risk of tunnel by method of BP neural network, avoid the occurrence of sudden flood water, which provides reference for risk prediction of water gushing in karst tunnel.
\end{abstract}

KEYWORD: karst tunnel; water inrush; BP neural network; risk prediction; advanced geological prediction

\section{INTRODUCTION}

With the Silk Road economic belt construction and vigorously promote the infrastructure construction in the western region in full swing, the construction of deep karst tunnel will more and more. Since the western region is extremely complicated hydrogeological conditions, the construction process water and mud outburst prone to disasters, causing a serious impact on the safety and duration of construction, the risk assessment and control of sudden gushing has become a key issue in karst tunnel construction which must be considered.

Domestic and foreign scholars has made many contributions. In engineering risk assessment studies in the risk assessment of karst tunnel, ITA issued Guidelines for Tunneling Risk Management (SøREN Degn Eskesen et al, 2004), domestic do lots of research work on risk assessment though later, then write Railway Tunnel Risk Assessment Interim Provisions (Ministry of Railway, 2007). Through the analysis of specific engineering cases, combining the characteristics of deep karst, Mao Bangyan summed up an important factor tunnel sudden gushing water and extract the deep-long tunnel deep karst water inflow risk assessment, establish a karst tunnel sudden gushing disaster risk assessment models with the use of comprehensive evaluation (MAO Bangyan, 2008). Zhou Zongqing extracted out of the influence of the tunnel sudden gushing of major geo- logical indicators according to the study of sudden gushing mechanism and controlling factors, based on the attribute recognition theory to sudden gushing risk assessment was discussed, and giving the corresponding engineering verification (ZHONG Zongqing et al, 2013). The method describe above, did not analysis the risk of sudden gushing factor weights in depth, and under different hydrogeological conditions, factors of weight differences, cannot be generalized. In this paper, based on BP neural network method statistics related engineering instance, the establishment of training samples and hydrogeological conditions, the tunnel sudden gushing risk rating, ensure construction safety.

\section{BP NEURAL NETWORK MODEL OF SUDDEN GUSHING RISK EVALUATION}

Karst tunnel gushing sudden risk assessment is by systematically analyze the impact of sudden gushing factors, risks tunnel sudden gushing forecast. The main objective in order to reflect the impact of sudden gushing factors studied by statistical analysis of cases related engineering methods, and reference to relevant literature (ZHONG Zongqing et al, 2013) (ZHANG Qingsong et al, 2009) (LI Liping et al, 2011) (GE Yanhui, 2010) (XU Zhenhao et al, 2011), analyzed the sudden gushing of hydrogeology and engineering geology environment, select the sudden 


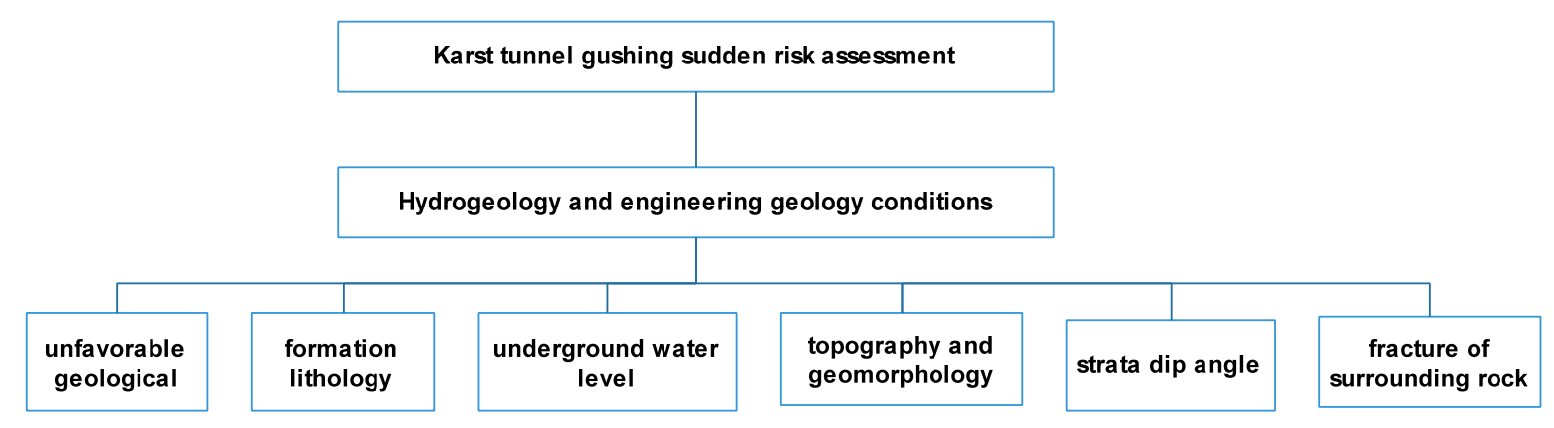

Fig. 1 hierarchical chart of water and mud in rush risk factors in Karst tunnel

BP network learning and training process owe two parts, forward propagation by the network input signal and the error signal reverse propagation, the signal is passed forward, error propagation direction. When the forward propagation, the input information transmitted to the output layer, each neuron output corresponding to the output layer of the network in response to the input mode from the input layer, hidden layer by layer by layer calculation; If system cannot get the desired output the output layer, the error into the back-propagation, by reducing the expected output and the actual output of the error in principle, from the output layer to the intermediate layers, and finally back to the input, correction layers each connection weights. With back propagation training ongoing, correct input mode network response rate is also rising, so the cycle until the error signal to within the permissible range so far (SU Bo et al, 2006).

\section{BP EVALUATION SYSTEM NEURAL NETWORK ANALYSIS}

\subsection{Evaluation System.}

Karst water burst is phenomenon which underground water storage conditions by outside interference power instability essentially. In this paper, hydrological and geological conditions influencing factors were evaluated.

A. Unfavorable geology. Water inrush tunnel construction are encountered with karst pipes, water - bearing fault zone, river and other adverse geological related.

B. Formation lithology. Tunnel water inrush disaster occurred in limestone, dolomite and other karst formations, lithology higher purity, the greater the layer thickness, the karst development, the more easily to form large karst pipeline (LI Shucai et al, 2014).
C. Underground water level. Groundwater plays a material carrier and the source of power in the dual role of water inrush process, is an important factor affecting water burst (LI Liping et al, 2011). Groundwater mainly in pore water, karst fissure water and water form, so that there is a strong disaster-causing ability of groundwater, and the energy in the form of groundwater depends mainly on groundwater level. Therefore, the water table and the floor of the tunnel elevation difference largely characterize the degree of danger of water inrush based on the groundwater table elevation difference $\mathrm{h}$ divided four levels, $\mathrm{h}$ $<0 \mathrm{~m}, 0 \mathrm{~m} \leq \mathrm{h}<30 \mathrm{~m}, 30 \mathrm{~m} \leq \mathrm{h} \leq 60, \mathrm{~h}>60 \mathrm{~m}$.

D. Topography and geomorphology. Water inrush in underground engineering is closely related to topography, surface karst depressions, sinkholes cause precipitation into the ground, called groundwater recharge source, direct influence of underground karst development.

E. Strata dip angle. Strata dip angle have a major impact on underground water flow angle is too large or too small is not conducive to karst. Strata dip angle is too big, small catchment area, the water cycle is weak; Strata dip angle is too small, is not conducive to the infiltration of surface water, karst development is also affected.

F. Fracture of surrounding rock. Tunnel Rock fractured situation to a large extent influence the size of water inflow, the fractured media penetration has unevenness, maximum permeability, and fracture and fracture permeability vertical direction parallel to the minimum (LIU Wei, 2014).

\subsection{Sudden gushing risk classification.}

Based on the above analysis, the tunnel sudden gushing risk classification index is determined by experience or expert score, after BP network training sample derived from the specific rates are shown in Table 1. 
Table 1 Expert scoring of risk factors for water inrush into karst tunnel

\begin{tabular}{|c|c|c|c|c|}
\hline \multirow{2}{*}{ factor } & \multicolumn{4}{|c|}{ Scores } \\
\hline & $75 \leq S \leq 100$ & $50 \leq \mathrm{S}<75$ & $25 \leq \mathrm{S}<50$ & $0 \leq \mathrm{S}<25$ \\
\hline unfavorable geology D1 & Strong hazard & Medium hazard & Weak hazard & No hazard \\
\hline formation lithology D2 & $80 \% \sim 100 \%$ & $50 \% \sim 80 \%$ & $20 \% \sim 50 \%$ & $0 \% \sim 20 \%$ \\
\hline underground water level D3 & $\mathrm{h}>60 \mathrm{~m}$ & $30 \mathrm{~m} \leq \mathrm{h} \leq 60$ & $0 \mathrm{~m} \leq \mathrm{h}<30 \mathrm{~m}$ & $\mathrm{~h}<0 \mathrm{~m}$ \\
\hline $\begin{array}{l}\text { topography and geomorphology } \\
\text { D4 }\end{array}$ & Large negative terrain & $\begin{array}{l}\text { Medium negative ter- } \\
\text { rain }\end{array}$ & $\begin{array}{l}\text { Small negative ter- } \\
\text { rain }\end{array}$ & $\begin{array}{l}\text { No negative ter- } \\
\text { rain }\end{array}$ \\
\hline strata dip angle D5 & $25^{\circ} \sim 65^{\circ}$ & $10^{\circ} \sim 25^{\circ}$ or $65^{\circ} \sim 80^{\circ}$ & $80^{\circ} \sim 90^{\circ}$ & $0^{\circ} \sim 10^{\circ}$ \\
\hline fracture of surrounding rock D6 & $\begin{array}{l}\text { Width greater than } \\
5 \mathrm{~mm}\end{array}$ & Width of $1 \sim 5 \mathrm{~mm}$ & $\begin{array}{l}\text { Width less than } \\
1 \mathrm{~mm}\end{array}$ & No fissure width \\
\hline
\end{tabular}

\subsection{BP neural network analysis of samples.}

Statistics tunnel water inrush accident related hydrogeological data, and refer to the relevant karst tunnel project example, to obtain a statistical sample, the statistical sample was subjected to BP neural network training, as the training samples. Water inrush accident in the tunnel, according to the sudden loss of water or disaster risk classification, specific classification in Table 2. Training sample data samples are shown in Table 3.

\section{ENGINEERING APPLICATIONS}

\subsection{Project overview.}

Tunnel repair using double points, lithology mainly sandstone, marl, slate, chert, phyllite, etc., rock crushing, abundant groundwater, fractured bedrock occurrence in the form of water, karst water and pore water, karst, groundwater level is higher than the tunnel floor about $150 \mathrm{~m}$, the construction of water and mud outburst prone to geological disasters.
Table 2 Tunnel water rush risk hierarchy table

\begin{tabular}{llll}
\hline Classification & $\begin{array}{l}\text { Water inrush Q } \\
\left(\mathrm{m}^{3} / \mathrm{h}\right)\end{array}$ & $\begin{array}{l}\text { Deaths } \\
\text { person }\end{array}$ & $\begin{array}{l}\text { Direct economic } \\
\text { losses / million }\end{array}$ \\
\hline I & $>10000$ & {$[30, \infty)$} & {$[1000, \infty)$} \\
II & $1000 \sim 10000$ & {$[10,30)$} & {$[500,1000)$} \\
III & $100 \sim 1000$ & {$[3,10)$} & {$[100,500)$} \\
IV & $10 \sim 100$ & {$[0,3)$} & {$[0,100)$} \\
\hline
\end{tabular}

Table 3 training sample data tables

\begin{tabular}{|c|c|c|c|c|c|c|c|c|}
\hline \multirow[b]{2}{*}{ Projects } & \multicolumn{8}{|c|}{ index } \\
\hline & D1 & D2 & D3 & D4 & D5 & D6 & $\begin{array}{l}\text { Overall } \\
\text { rating }\end{array}$ & grade \\
\hline 1 & 88 & 90 & 67 & 83 & 60 & 75 & 87 & II \\
\hline 2 & 80 & 90 & 90 & 65 & 60 & 67 & 86 & I \\
\hline 3 & 69 & 35 & 89 & 50 & 80 & 61 & 73 & II \\
\hline 4 & 82 & 70 & 86 & 81 & 63 & 63 & 72 & II \\
\hline 5 & 85 & 75 & 76 & 25 & 87 & 80 & 79 & I \\
\hline 6 & 90 & 80 & 78 & 30 & 87 & 85 & 83 & I \\
\hline 7 & 73 & 91 & 59 & 67 & 50 & 47 & 69 & II \\
\hline 8 & 67 & 39 & 27 & 31 & 36 & 19 & 41 & III \\
\hline 9 & 81 & 83 & 77 & 81 & 79 & 86 & 82 & I \\
\hline 10 & 77 & 81 & 72 & 86 & 67 & 79 & 83 & I \\
\hline 11 & 67 & 76 & 72 & 71 & 63 & 70 & 70 & II \\
\hline 12 & 69 & 72 & 61 & 64 & 73 & 67 & 68 & II \\
\hline 13 & 79 & 81 & 90 & 84 & 67 & 82 & 78 & I \\
\hline 14 & 73 & 87 & 61 & 62 & 56 & 72 & 71 & II \\
\hline 15 & 87 & 91 & 65 & 81 & 72 & 78 & 81 & I \\
\hline 16 & 89 & 82 & 84 & 79 & 81 & 74 & 86 & I \\
\hline
\end{tabular}

\subsection{Risk rating.}

In predicted zone of tunnel, strata dip $20^{\circ}$, karst content of about $90 \%$, surrounding rock grade level is $\mathrm{V}$, the negative terrain area ratio of about $65 \%$, relatively rock crushing, fissures and cracks joint water gush from fissures around the working face, showing rain shape. Experts rate obtained after scoring vector $\mathrm{D}=[\mathrm{D} 1, \mathrm{D} 2, \mathrm{D} 3, \mathrm{D} 4, \mathrm{D} 5, \mathrm{D} 6]=$ $[87,89,93,77,69,76]$, calculated by BP neural network integrated score of 85 , the risk level to I grade.

\section{CONCLUSION}

A risk assessment carried out in karst tunnel based on BP neural network. According to the hydrological and geological conditions of the tunnel site and refer to the relevant literature, selecting unfavorable geology, formation lithology, underground water level, topography and geomorphology, strata dip angle, fracture of surrounding rock, as the tunnel wall rock fissure water inrush risk assessment. The application of BP neural network model of tunnel water inrush risk were evaluated. The disaster of Karst water burst has many factors, this paper considers only the hydrogeological factor that influence them, without considering factors engineering. Therefore, it is necessary to combine engineering factors Karst water inrush risk for further study. 


\section{REFERENCES}

GE Yanhui. Study on water inrush risk and early warning mechanism of karst tunnel [D].Jinan: Shandong University, 2010.

LI Liping, LI Shucai, CHEN Jun, et al. Construction license mechanism and its application based on karst water inrush risk evaluation [J].Chinese Journal of Rock Mechanics and Engineering, 2011, 30(7)1345-1355.

LI Shucai, ZHANG Qingsong. The mechanism and treatment of water inrush for tunneling and underground projects [M]. China Communications Press, 2014.

LIU Wei. Research on prediction of water inrush in deep-long tunnel under BP neural network and numerical simulation [D].Changsha: Central South University, 2014.

MAO Bangyan. Modern deep karst formation mechanism and evaluation of control action on cross-mountain tunnel [D].Chengdu: Chengdu University of Technology, 2008.

Ministry of Railway, the People's Republic of China. Railway tunnel risk assessment interim provisions [S]. Beijing: China Railway Publishing House, 2007.

SøREN Degn Eskesen, Tengborg PER, JøGEN Kampmann, et al. Guidelines for tunnelling risk management: International tunnelling, association, working group No. 2. Tunneling and Underground Space Technology, 2004, 19:217- 237.

SU Bo, LIU Lu, YANG Fangting. Comparison and research of grain production forecasting with methods of $\mathrm{GM}(1, \mathrm{~N})$ gray system and BPNN [J].Journal of China Agricultural University, 2006, 11(4):99-104.

XU Zhenhao, LI Shucai, LI Liping, et al. Risk assessment of water or mud inrush of karst tunnels based on analytic hierarchy process [J].Rock and Soil Mechanics, 2011,32(6): 1757-1766.

ZHANG Qingsong, LI Shucai, HAN Hongwei, et al. Study on risk evaluation and water inrush disaster preventing technology during construction of karst tunnels [J].Journal of Shandong University(Engineering Science),2009,39 (3): 106110.

ZHONG Zongqing, LI Shucai, LI Liping, et al. Attribute recognition model of fatalness assessment of water inrush in karst tunnels and its application [J].Rock and Soil Mechanics, 2013,34(3): 818-826. 